\title{
Editorial
}

\section{A Winner to Celebrate, and a New Year to Look Forward To}

The editorial board is delighted to announce that Medical History's William Bynum Essay Prize for 2017 was awarded to Kathleen Pierce (Rutgers, the State University of New Jersey, USA) for her entry 'Photograph as Skin, Skin as Wax: Indexicality and the Visualization of Syphilis in Fin-de-Siècle France'. The runner up was Annelie Drakman (Department of History of Science and Ideas, Uppsala University, Sweden) with her entry 'The Social Construction of Pathogenic Dirt: Changing Interactions Between Medicine and Cleanliness Practices in the Nineteenth Century'. We offer our warmest congratulations to Kathleen, and our thanks to all those who entered for their interest in the journal and for once again making this such a competitive prize. A special mention of thanks must also go to the Prize Committee, chaired by Professor William Bynum himself and this year comprising Professor Magali Romero Sá and Dr Sabine Clarke, who selected the winner.

The journal continues to thrive, thanks to constant support provided by Cambridge University Press and Alexander Medcalf's tireless efforts on behalf of us all. We are approaching a year when we will reshuffle the editorial advisory board membership in order to bring in new energies and ideas. Those leaving the board will, I hope, join us again in the future, as we keep changing its structure to create new collaborative capacities and possibilities. We also look forward to working with authors old and new, whose ideas and hard work continue to sustain Medical History.

SANJOY BHATTACHARYA

Centre for Global Health Histories and Department of History, University of York, UK

Email: sanjoy.bhattacharya@york.ac.uk 